\section{RV OUTFLOW}

TRACT

REVALVULATION

\title{
Right ventricular outflow tract revalvulation using the Melody Valve: The next frontier
}

\section{D.G. Buys and S.C. Brown}

Division of Paediatric Cardiology, University of the Free State, Bloemfontein, South Africa

Institution at which work was performed: Universitas Hospital, Bloemfontein, South Africa

\section{Address for correspondence: \\ Prof S.C. Brown \\ Paediatrics G69 \\ PO Box 339 \\ University of the Free State \\ Bloemfontein \\ 9300 \\ South Africa}

Email:

gnpdscb@ufs.ac.za

\section{INTRODUCTION}

Various congenital heart lesions with anatomical abnormalities involving the right ventricular outflow tract (RVOT) will require surgical repair early in childhood. Classical lesions include tetralogy of Fallot, pulmonary atresia and truncus arteriosus. A significant number of these will, over time, develop additional problems of the RVOT which will need to be addressed in order to prevent right ventricular dysfunction

\section{SURGICAL REVALVULATION}

Surgery has been the preferred method of establishing RVOT revalvulation. It has traditionally been reserved for children older than 3 years. Surgical revalvulation consists of the implantation of allo- or xenografts. Pulmonary homografts are generally preferred, but other valves e.g. Contegra ${ }^{\circledR}$ or prosthetic conduits are also being used. Due to improvements in surgical techniques, mortality for re-operation has declined and is now in the region of 3.7\%.

However, failure of the conduit eventually occurs because of limited longevity. Conduit degeneration is observed in more than $75 \%$ of homografts over time. Lifespan of conduits are measured

\section{ABSTRACT}

Congenital heart lesions with abnormal right ventricular outflow tract anatomy will require early surgical intervention. Re-intervention rates in these patients are high due to homograft degeneration. Until recently, surgery was the only treatment option for right ventricular outflow tract dysfunction. Percutaneous pulmonary valve implantation has been introduced as a new therapeutic alternative to prolong conduit life span and to reduce surgical re-intervention rates. Short- and mid-term results have been favourable and showed that it is a safe and effective therapy. These are reviewed with emphasis on the Melody valve.

SAHeart 20।3; 10:448-453

in terms of years of freedom from re-operation. Freedom from re-operation varies (see Table I) with rates of $97 \%$ at one year to, on average, $70 \%$ and $31 \%$ after 10 and 15 years respectively. ${ }^{(1-3)}$ Low body weight, younger age at insertion, small size grafts and longer cross-clamping times are factors associated with early graft failure. ${ }^{(1,4)}$ It has been estimated that these patients may require up to 5 conduit revisions over a lifetime.

Multiple conduit revisions in these patients often result in prolonged hospital stays, increased morbidity and mortality due to the fact that difficulty of surgery increases with every re-operation. This may result in a considerable increase in medical costs and a negative impact on quality of life. Nevertheless, surgery has good long term survival and should be considered as the gold standard of treatment.

\section{PERCUTANEOUS RVOT REVALVULATION}

Until recently, surgery was the only option for managing RVOT dysfunction. The first percutaneous pulmonary valve was implanted

TABLE I: Freedom from surgical re-intervention

\begin{tabular}{|l|c|c|c|c|c|c|}
\hline & \multicolumn{7}{c}{ Freedom from re-intervention (\%) } \\
\hline Series & Number(n) Published & ly & $5 y$ & $10 y$ & $15 y$ \\
\hline Kim $^{(1)}$ & 112 & 2011 & 97 & 77 & 35 & \\
\hline Dearnari(3) $^{(3)}$ & 1095 & 2003 & & & 55 & 32 \\
\hline Stark $^{(2)}$ & 656 & 1998 & & 84 & 58 & 31 \\
\hline
\end{tabular}


TABLE 2: Melody ${ }^{\circledR}$ valve: Indications and contraindications

\begin{tabular}{l|l|}
\hline Inclusion criteria & Exclusion criteria \\
\hline Weight $\geq 30 \mathrm{~kg}$ & Unfavorable coronary artery anatomy \\
\hline $\begin{array}{l}\text { Conduit size } \geq 16 \mathrm{~mm} \\
\text { Dysfunctional RVOT conduits }\end{array}$ & Central vein obstruction \\
$\begin{array}{l}\text { with clinical indication for } \\
\text { reintervention, and either: } \\
\text { Regurgitantion: } \geq \text { moderate } \\
\text { regurgitation or }\end{array}$ & accommodate a 22-Fr size introducer \\
\hline $\begin{array}{l}\text { Stenosis: } \text { mean RVOT gradient } \\
\geq 35 \mathrm{mmHg}\end{array}$ & Pregnancy \\
\hline
\end{tabular}

in the year 2000 by Professor Philippe Bonhoeffer. ${ }^{(5)}$ This work resulted in the development of the Melody ${ }^{\circledR}$ valve (Medtronic, Minneapolis, MN, USA), which is a dedicated percutaneous pulmonary valve which is now commercially available. The Edwards SAPIEN transcatheter heart valve (Edwards Lifesciences, Inc., Irvine, California) was initially developed for patients with severe aortic stenosis. This valve has since been used and adapted for RVOT dysfunction in the pulmonary position. ${ }^{(6)}$ The current Melody ${ }^{\circledR}$ valve is available in $18-22 \mathrm{~mm}$ diameters and the Edwards SAPIEN valve in 23 and $26 \mathrm{~mm}$ sizes.

\section{CURRENT INDICATIONS FOR PERCUTANEOUS PULMONARY VALVE IMPLANTATION}

Only patients meeting indications for surgical re-intervention qualify for consideration of valve implantation. Clinical and morphological indications and contraindications for Melody ${ }^{\circledR}$ valve implantation can be viewed in Table 2.

\section{DIAGNOSTIC EVALUATION}

Patients with right ventricle to pulmonary artery (RV-PA) conduit dysfunction need to be evaluated for possible percutaneous pulmonary valve implantation (PPVI). ECG holter is performed to identify possible arrhythmias and for calculation of QRS intervals. Objective functional assessment to determine exercise capacity can be done by measuring the peak oxygen uptake (VO2max) and anaerobic threshold derived from respiratory gas analysis during maximal exercise testing. (7-9) Transthoracic echocardiography is used to determine right ventricular pressure load, size and categorical assessment of pulmonary regurgitation. However, echocardiographic right ventricular functional assessment does not correlate well with cardiac magnetic resonance imaging (MRI). ${ }^{(10,11)}$
Pulmonary regurgitation severity should be assessed and classified. RVOT anatomy, RV-PA mean gradients, mitral- and tricuspid regurgitant jets can yield valuable information. ${ }^{(8-1)}$

High resolution computed tomography (CT) angiography of the RVOT gives important information regarding RVOT anatomy and the spatial relationship to the coronary arteries. ${ }^{(8)} \mathrm{CT}$ angiography does, however, have added radiation exposure compared to MRI. Cardiac MRI gathers valuable information regarding ventricle mass, function and volumes and is currently the preferred investigation. . $^{(7,8,13)}$

\section{TECHNICAL ASPECTS OF RVOT REVALVULATION BY MEANS OF THE MELODY ${ }^{\circledR}$ VALVE}

The Melody ${ }^{\circledR}$ valve consists of a segment of modified-bovine jugular vein sutured into a platinum iridium stent of $34 \mathrm{~mm}$ in length. The valve can be crimped down to $6 \mathrm{~mm}$ and re-expanded from a minimum of $18 \mathrm{~mm}$ to a maximum of $22 \mathrm{~mm}$ (Figure $\mid \mathrm{A}$ ).

\section{Delivery system}

The Ensemble transcatheter delivery system was designed for percutaneous Melody ${ }^{\circledR}$ valve implantation and consists of a balloonin-balloon structure with a retractable sheath for valve covering post crimping. The system is $100 \mathrm{~cm}$ in length and has an outer diameter of 22Fr size (Figure IB).

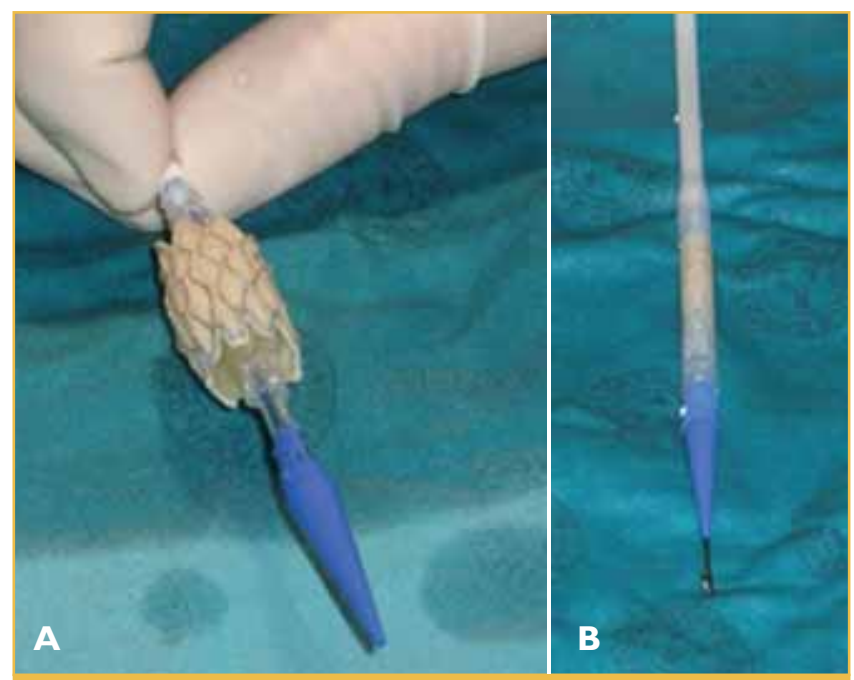

FIGURE I: Melody ${ }^{\oplus}$ valve and Ensemble delivery catheter (A) The valve is partially crimped over the balloon portion of the catheter. (B) The valve can be seen fully crimped and covered with the outer sheath. 

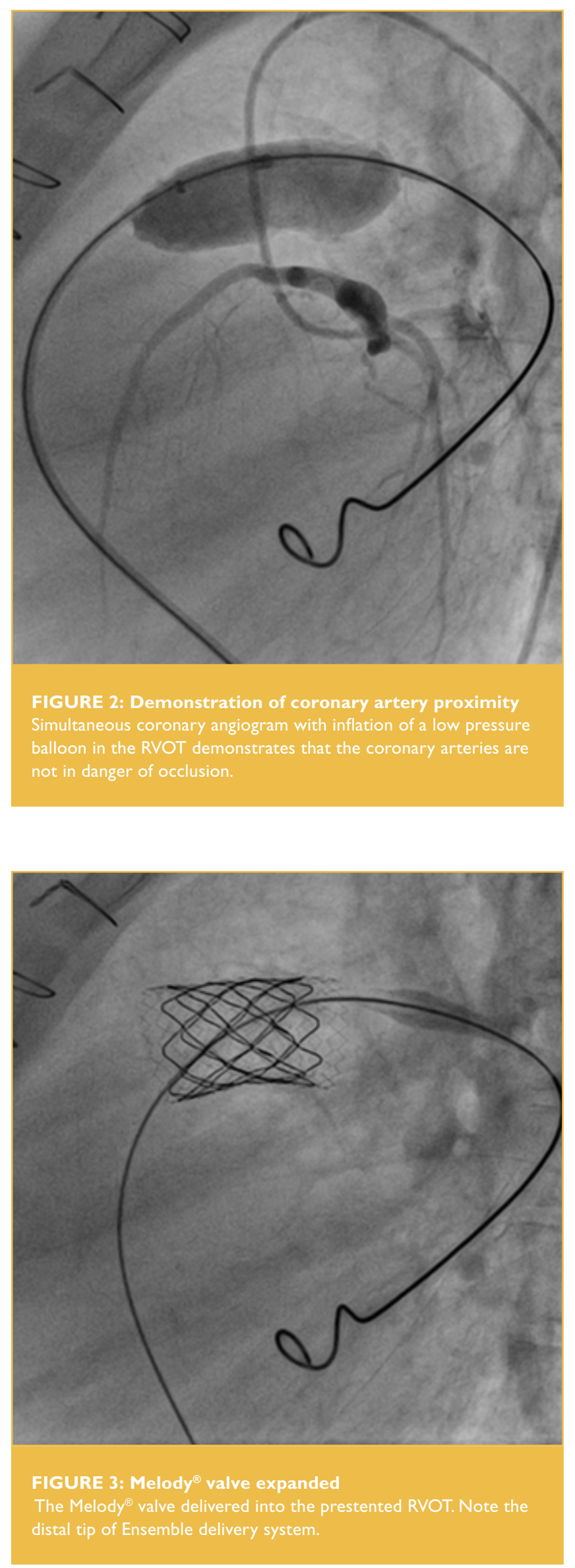

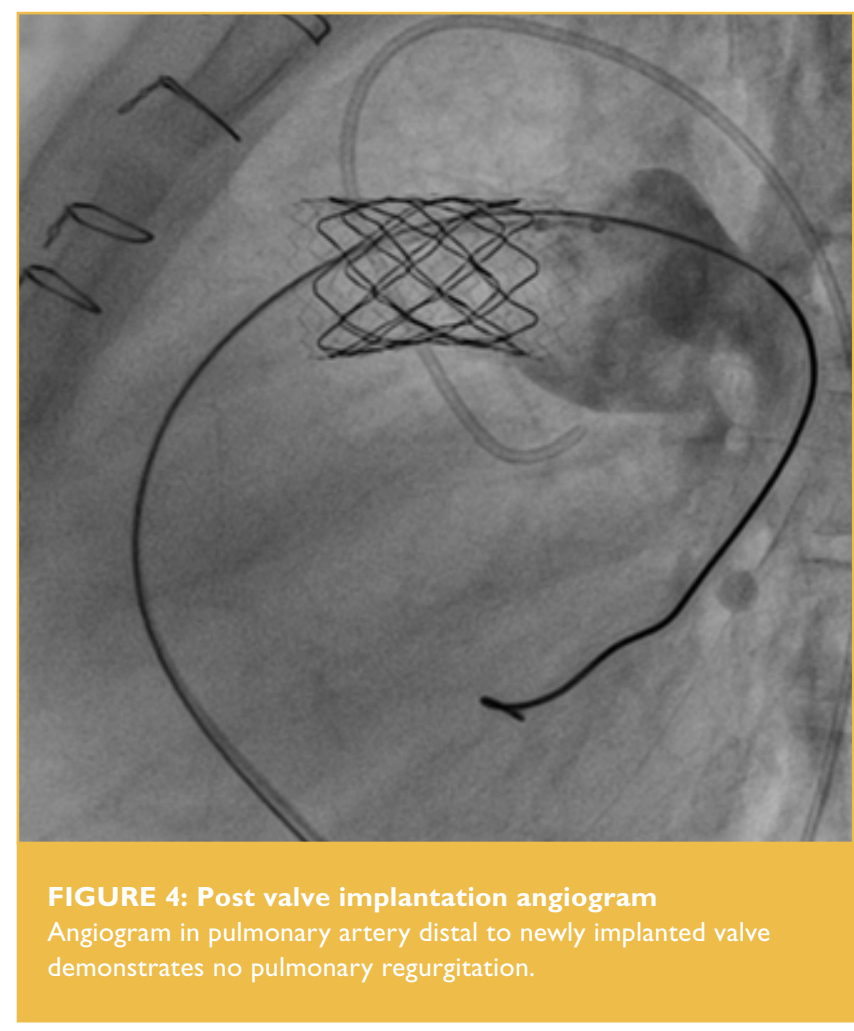

Procedural aspects

Central venous accesses, preferably femoral access is obtained. Right and left heart catheterisation with a full set of hemodynamic calculations is performed. Patients meeting the inclusion criteria will then undergo simultaneous coronary angiography and inflation of a low pressure balloon in RVOT to exclude coronary artery compression (Figure 2). ${ }^{(8,10)}$ Absence of ischemic ECG changes in combination with normal coronary angiography information will be reassuring for continuation of the procedure.

Use of a stiff guidewire [Meier (Boston Scientific, Natick, MA, USA), Lunderquist $^{\mathrm{TM}}$ Extra Stiff (COOK Medical., Bloomington, USA) and Amplatz Ultra Stiff (COOK Medical, Bloomington, USA)] in a safe and stable position is of critical importance and will prevent serious complications such as pulmonary artery perforations.

Preparing the "landing zone" for Melody ${ }^{\circledR}$ valve implantation is a crucial step in the procedure. This is done by predilating and prestenting the RVOT. High pressure balloons [Mullins-X Ultra high pressure (NuMED, Hopkinton, NY, USA) or Bard Atlas ${ }^{\circledR}$ PTA balloons (Bard Peripheral Vascular, Tempe, AZ, USA)] and stents with a high radial strength are preferred [Andra stent (Andramed $\mathrm{GmbH}$, Reutlingen, Germany), Intrastent Max LD (ev3 Endovascular, Plymouth, USA)]. The decision to use a covered or bare 
metal stent for pre-stenting will be influenced by the risks of homograft rupture. Most operators would nowadays prefer to use a long covered stent $(\geq 45 \mathrm{~mm})$ in a homograft since calcified, crimped homografts fracture if dilated. In these patients flaring proximal and distal ends to appose tightly to the surrounding tissues at the proximal and distal anastomsis would be important. It is essential to create a stable Melody ${ }^{\circledR}$ landing site and any recoil during pre-stenting should lead to additional stenting. It is important to note that any residual RVOT gradient $>15 \mathrm{mmHg}$ should not be accepted prior to valve deployment.

Once RVOT rehabilitation has been performed, the Melody ${ }^{\circledR}$ valve is delivered in an appropriate position (Figure 3). Repeat hemodynamic assessment and angiography are performed to evaluate the result (Figure 4). Residual gradients can be treated with high pressure balloon dilatation after valve implantation. Cardiothoracic backup is desirable during the procedure.

\section{OUTCOMES OF PERCUTANEOUS PULMONARY VALVE IMPLANTATION}

More than 3000 valves have been implanted worldwide and overall mortality is very low $(0 \%$ - $1 \%){ }^{(7,10,12,14-17)}$ Procedural success for attempted percutaneous valve implantation is excellent. The most common exclusion factor has been the risk of coronary compression. Significant reduction in outflow tract gradient and/or abolishment of pulmonary regurgitation was observed in all cases. Right ventricular volumes also improved markedly.

Major procedural complications included dislodgement of the valve, coronary compression, rupture of homograft and haemothorax due to pulmonary artery perforations. ${ }^{(7,13-18)}$ Dislodgement of the device occurred mostly during the initial development phase and could be related to operator inexperience as well as the early learning curve. It is now extremely rare, especially with pre-stenting. Coronary compression was responsible for virtually all deaths resulting from percutaneous revalvulation. Since this is a potentially avoidable complication, pre-selection with sophisticated imaging modalities as mentioned have become essential. Rupture of homograft conduits is a rare, but ever present risk. Therefore, making routine use of a covered stent or at least having one of these available during the procedure is essential. The pulmonary arteries may be perforated by the very stiff guidewires employed to deliver the valve. In the worldwide experience, some resolved spontaneously, could be treated by implanting a covered stent to seal off the perforation or required a thoracotomy. Overall, early complications were rare during percutaneous procedures, occurring in less than $8.5 \%$ of implantations. ${ }^{(8,16,17)}$ This compares favorably to surgical series where early complications have been described in up to $9.6 \%$ of patients. ${ }^{(18)}$

Follow-up results for outcome are now short to mid-term. The most common complication has been stent fractures which occurred in $5 \%$ to $30 \%$ of cases. ${ }^{(14,15,19)}$ Although the vast majority of stent fractures remain asymptomatic, it may lead to the development of outflow tract gradients. However, this can easily be treated with the implantation of another percutaneous valve. This problem is likely to decrease due to the current practice of routine right ventricular outflow tract pre-stenting. Although extremely rare, endocarditis is a vexing problem and the most common reason for valve explantation. ${ }^{(20)}$

Freedom from valve dysfunction or re-operation ranged from 95 - 100\% at one year to $70 \%$ at seventy months during followup. $^{(8,14,15)}$ These results provide evidence that the initial aim of prolonging the life-span of surgically placed right ventricular outflow tract conduits can be successfully achieved by the implantation of a percutaneous valve.

Cost analyses have been favourable. Although the valve itself is expensive, the low morbidity and short hospital stay makes total cost comparable to that of surgery. ${ }^{(21)}$ It should be pointed out that cost comparisons for South Africa are currently not available. The main benefits of percutaneous pulmonary valve implantations are the low risks, short hospital stays, delay in the need for surgery and improvement in quality of life.

\section{TIMING OF RIGHTVENTRICLE OUTFLOW TRACT REVALVULATION: THE CONTROVERSY}

Right ventricular outflow tract dysfunction is one of the most common killers in congenital heart diseases. Although the indications for intervention in stenosis are clearly defined, the same cannot be said for pulmonary valve regurgitation. As a matter of fact, it is a well-established fact that some patients with pulmonary regurgitation and dilated right ventricles show little improvement after right ventricular outflow tract revalvulation. Optimal timing of surgery in this subgroup of patients is not clear and remains controversial. The reason for this is that we currently do 
not know how much overload a right ventricle can tolerate before irreversible damage sets in.

Patients with pulmonary regurgitation present with dilated right ventricles because of the increased volume loads on the ventricles. Studies in post-operative patients with tetralogy of Fallot and pulmonary regurgitation have shown abnormal right ventricular deformation indices despite normal global right ventricular function. ${ }^{(22)}$ Right ventricular ejection fractions assessed by cardiac MRI were normal, signifying that right ventricle systolic function parameters only become abnormal late in RVOT dysfunction and long after dysfunction at cellular level was present. In another study in elite cyclists, a disproportionate incidence of ventricular tachycardia and sudden death was observed. ${ }^{(23)}$ Dilation of their right ventricles was demonstrated and ascribed to the large volume loads on the heart during frequent peak exercise. This caused right heart injury resulting in electrical dysfunction as the presenting symptom. It is important to take note of the fact that the dysrrhytmias in all the athletes occurred before measurable right ventricular dysfunction became apparent.

Compare this to patients with right ventricular outflow tract dysfunction - we know that it leads to right heart dilation and that a significant number die unexpectedly due to arrhythmias. Furthermore, these dilated right ventricles have normal or near normal function on MRI. All these findings suggest that electrical and cellular level dysfunction set in long before global mechanical dysfunction becomes apparent. If we allow too much time to pass before revalvulation, irreparable damage may occur to the right ventricle explaining the poor results of revalvulation in some patients. In the past, physicians tended to wait as long as possible before intervening due to the risks and morbidity associated with surgery. In this new era of percutaneous valves, one may thus consider revalvulation at an earlier age in order to preserve right ventricular mechanics. As a result, some physicians advocate intervention in these patients before they become symptomatic. However, at present we still do not have the ability to accurately measure when it is time to intervene in asymptomatic patients and the timing of intervention is bound to remain controversial until we can scientifically define measureable right ventricle parameters to guide the decision.

\section{FUTURE DEVELOPMENTS}

New developments consist of mounting valves on stronger stents and a new version of the Melody ${ }^{\circledR}$ valve will soon become available.
Also, valves are being developed for larger outflow tracts which cannot be treated with the current valve sizes available. This has been a limiting factor in some patients, especially patients with dilated outflow tracts. Recent studies have also shown that the valve can be implanted in selected cases in younger patients $(<20 \mathrm{~kg})$ and has even been used during hybrid procedures to avoid cardiac bypass. ${ }^{(24)}$ Surgeons are also adapting techniques at initial procedures to construct conduit angles amenable to transcatheter intervention and at a safe distance from the coronary arteries.

\section{CONCLUSION}

Percutaneous pulmonary valves are a safe and effective therapy for revalvulation of the right ventricular outflow tract. The stented valves can be implanted with a high success rate as well as low morbidity and mortality. Results have proven that percutaneous pulmonary valves extend the lifespan of conduits. It is important to realise that percutaneous revalvulation is complimentary to surgery and not in competition with surgical revalvulation. The availability of percutaneous valves may change the way in which we approach right ventricular revalvulation in the future, but remains controversial at present for certain indications.

\section{Conflict of interest: none declared.}


I. Kim H, Dong-Man S, Hong Ju S, et al. Long term results of right ventricular outflow tract reconstruction with homografts. Korean J Cardiovasc Surg 20 I |;44: I 08- I | 4.

2. Stark J, Bull C, Stajevic M, et al. Fate of subpulmonary homograft conduits: determinants of late homograft failure. J Thorac Cardiovasc Surg 1998; I 15:506-5 16.

3. Dearani JA, Danielson GK, Puga J. Late follow-up of I 095 patients undergoing operation for complex congenital heart disease utilising pulmonary ventricle to pulmonary artery conduits. Ann Thorac Surg 2003;75:399-4I I.

4. Boetig D, Goerler H, Westhoff-Bleck M, et al. Evaluation of 188 consecutive homografts implanted in pulmonary position after 20 years. Eur J Cardiothorac Surg 2007;32: 1 33-142.

5. Bonhoeffer P, Boudjemline $Y$, Saliba Z, et al. Percutaneous replacement of pulmonary valve in a right-ventricle to pulmonary artery prosthetic conduit with valve dysfunction. Lancet 2000;35: I 403-1405.

6. Peter Ewert, Eric Horlick, Felix Berger. First implantation of the CE-marked transcatheter Sapien pulmonic valve in Europe. Clin Res Cardiol 2012;100(1):85-87.

7. Khambadkone S, Coats L, Taylor A, et al. Percutaneous Pulmonary valve implantation in humans: results in 59 consecutive patients. Circulation 2005;1 12: I189-1197.

8. Zahn EM, Hellenbrand WE, Lock JE, et al. Implantation of the melody transcatheter pulmonary valve in patients with a dysfunctional right ventricular outflow conduit: early results from the U.S. clinical trial. J.Am. Coll Cardiol 2009;54: 1722-1729.

9. Khambadkone S, Bonhoeffer P. Percutaneous pulmonary valve implantation. Semin Thorac Cardiovasc Surg Pediatr Card Surg Ann. 2006;02:006.

10. Zahn EM, Hellenbrand WE, LockJE, et al. Implantation of the melody transcatheter pulmonary valve in patients with a dysfunctional right ventricular outflow tract conduit. JACC 2009; 18:1722-1729.

1।. Brown DW, McElhinney DB, Araoz PA, et al. Reliability and accuracy of echocardiographic right heart evaluation in the US Melody valve investigational trial. J Am Soc Echocardiogr 2012;25:383-392.

12. Lurz P, Coats L, Khambadkone S, et al. Percutaneous Pulmonary valve implantation: Impact of evolving technology and learning curve on clinical outcome. Circulation 2008; 1 17:1964-1972.

13. Khambadkone S, Bonhoeffer P. Nonsurgical pulmonary valve replacement: Why, when and how? Catheter Cardiovasc Interv 2004;62:40 I-408.

14. Eichen A, Ewert P, Hager A, et al. Percutaneous pulmonary valve implantation: Two-centre experience with more than 100 patients. Eur Heart J 201 1;32: 1260-1265.

15. McElhinney DB, Hellenbrand WE, Zahn E, et al. Short- and medium-term outcomes after transcatheter pulmonary valve placement in the expanded US Melody Valve trial. Circulation 2010; 122:507-516.

16. Lurz P, Gaudin R, Taylor AM, et al. Percutaneous pulmonary valve implantation. Semin Thoracic Cardiovasc Surg Pediatr Card Surg Ann 2009; 12:1 12 - 117.

17. Coats L, Tsang V, Khambadkone S, et al. The potential impact of percutnaous pulmonary valve stent implantation on right ventricular outflow tract re-intervention. Eur J Cardiothorac Surg 2005;27:536-543.

18. Coats L, Tsang $\vee$, Khambadkone $S$. The potential impact of percutaneous pulmonary valve stent implantation on right ventricular outflow tract re-intervention. Eur J Cardiothorac Surg 2005;27:536-543.

19. Nordmeyer J, Khambadkone S, Coats L, et al. Risk stratification, systematic classification and anticipatory management for stent fracture after percutaneous pulmonary valve implantation. Circulation 2007; | 15:1392-1397.

20. Patel $M$, Iserin $L$, Bonnet $D$, et al. Atypical malignant late infective endocarditis of Melody valve. J Thorac Cardiovasc Surg 2012;143:32-5.
21. Raikou M, McGuire A, Lurz P, et al. An assessment of the cost of percutaneous pulmonary valve implantation versus surgical pulmonary valve replacement in patients with right ventricular outflow tract dysfunction. J Med Econ 2011:14; 47-52.

22. B Eyskens, SC Brown, $\mathrm{P}$ Claus, et al. The influence of pulmonary regurgitation on regional right ventricular function in children after repair of tetralogy of Fallot. Eur J Echocard 2010;1 1:341-345.

23. Heidbüchel $H$, Hoogsteen J, Fagard R, et al. High prevalence of right ventricular involvement in endurance athletes with ventricular arrhythmias. Eur Heart J 2003:24:1473-1480.

24. Vezmar M, Chaturvedi R, Lee K, et al. Percutaneous pulmonary valve implantation in the young. JACC 2010:3;439-448. 